\title{
Patient Education for Informed Decision Making About Prostate Cancer Screening: A Randomized Controlled Trial with 1-Year Follow-Up
}

Robert J. Volk, $P b D^{1}$

Stephen J. Spann, $M D^{1}$

Alvab R. Cass, MD, $S M^{2}$

Sarab T. Hawley, $P b D^{1}$

${ }^{1}$ Department of Family and Community Medicine, Baylor College of Medicine,

${ }^{2}$ Department of Family Medicine The University of Texas Medical Branch, Galveston, Tex Houston, Tex

\begin{abstract}
PURPOSE The efficacy of prostate cancer screening is uncertain, and professional organizations recommend educating patients about potential harms and benefits. We evaluated the effect of a videotape decision aid on promoting informed decision making about prostate cancer screening among primary care patients.
\end{abstract}

METHODS A group of 160 men, 45 to 70 years of age, with no history of prostate cancer, were randomized to view or not to view a 20-minute educational videotape before a routine office visit at a university-based family medicine clinic. The subjects were contacted again 1 year after their visit to assess their receipt of prostate cancer screening (digital rectal examination [DRE] or prostate-specific antigen [PSA] testing), their satisfaction with their screening decision, and knowledge retention since the baseline assessment.

RESULTS Follow-up assessments were completed for $87.5 \%$ of the intervention subjects and $83.8 \%$ of the control subjects. The rate of DRE did not differ between the 2 groups. Prostate-specific antigen testing was reported by 24 of $70(34.3 \%)$ intervention subjects and 37 of $67(55.2 \%)$ control subjects $(P=.01)$. African American men were more likely to have had PSA testing (9 of $16,56.3 \%)$ than were white men (13 of $46,28.3 \%)(P=.044)$. Satisfaction with the screening decision did not differ between the study groups. Intervention subjects were more knowledgeable of prostate cancer screening than were control subjects, although these differences declined within 1 year $(P<.001)$.

CONCLUSIONS Decision aids for prostate cancer screening can have a long-term effect on screening behavior and appear to promote informed decision making.

Ann Fam Med 2003;1:22-28. DOI: 10.1370/afm.7

\section{INTRODUCTION}

$\mathrm{P}$ rostate cancer is a common disease in the United States, with an estimated 198,100 new cases and 31,500 deaths attributed to the disease in 2001. ${ }^{1}$ Although early detection of prostate cancer may

Conflicts of interest: None reported decrease its associated morbidity and mortality, there remains uncertainty about the benefits of screening for prostate cancer. This uncertainty has led professional organizations to offer guidelines promoting informed decision making about screening. Whether generally favoring or rejecting the regular use of prostate cancer screening, most national organizations now support the concept of patient-informed decision making on this issue. ${ }^{2-5}$ Although their recommendations for prostate cancer screening are framed differently, the underlying message of several national guidelines suggests that "...the physician's job is to discuss the potential bene- 
fits and risks of screening with the patient, leaving the ultimate decision up to him. ${ }^{\prime 6}$ Herein lies a challenge for the primary care physician.

Many patient education materials have been developed specifically to help patients make informed decisions about prostate cancer screening; these materials include printed brochures, patient informed-consent forms, and videotapes. ${ }^{7-11}$ Although studies suggest that decision aids can increase knowledge about prostate cancer and encourage informed decision making, the effect of decision aids on actual receipt of prostate-specific antigen (PSA) testing is variable. ${ }^{12}$ Furthermore, the follow-up period in these studies is often too short to allow us to assume that screening has or has not taken place as a result of the intervention.

In a previous study, ${ }^{13}$ we evaluated one decision aid, The PSA Decision: What YOU Need to Know, originally developed by the Foundation for Informed Medical Decision Making, Inc. The results of a 2 -week followup indicated that a videotape decision aid increased knowledge about prostate cancer and decreased a preference for obtaining PSA screening. In this subsequent study, we report the results of a 1-year follow-up, assessing the long-term impact on these patients of the decision aid with regard to subsequent screening behaviors, satisfaction with the decision to be or not to be screened, and retention of knowledge. The hypothesis guiding this analysis is that a videotaped education decision aid for promoting informed decision making about prostate cancer will result in a lower rate of screening while increasing patient satisfaction and knowledge.

\section{METHODS}

\section{Participants}

Details of the study procedures, subjects, and 2-week follow-up results can be found elsewhere. ${ }^{13}$ Eligible subjects were male primary care patients who were 45 to 70 years of age, who had no history of prostate cancer, and who presented for care at the Family Medicine Center at The University of Texas Medical Branch in Galveston, Tex. Clinic appointment lists and computerized patient records were reviewed to identify potentially eligible patients. Research assistants then contacted patients by telephone before a scheduled office visit and solicited their participation. The target enrollment of 160 subjects was reached after 24 patients refused participation and 25 were found to be ineligible.

\section{Procedures}

Subjects were asked to arrive 30 to 45 minutes before their scheduled office visit. Research assistants, who were blinded to the original group assignments, reviewed the study protocol with subjects and obtained written informed consent. Subjects were randomly assigned to view the videotape (intervention group) or receive no information about prostate cancer screening (control group). Randomization by permuted blocks was used to balance the number of subjects in each arm of the study. Subjects then completed a self-report baseline questionnaire on their screening practices and knowledge. Subjects assigned to the intervention group viewed the videotape before seeing their health care providers.

Two weeks after the baseline office visit, all subjects were contacted by telephone for a follow-up assessment. In addition, the control subjects were mailed an information pamphlet on prostate cancer screening. One year after the baseline office visit, a telephone assessment was conducted to determine the subjects' screening behaviors and assess their knowledge retention.

Study research assistants conducted recruitment, subject allocation, and data collection. The study was approved by the Institutional Review Board at the University of Texas Medical Branch for use of human subjects.

\section{Intervention Group}

The intervention had been described previously in detail. ${ }^{13}$ We used the videotape The PSA Decision: What YOU Need to Know, developed by the Foundation for Informed Medical Decision Making, Inc. This 20minute videotape presents the potential risks and benefits of PSA testing in men 50 years of age and older. It uses physician actors who articulate the advantages and disadvantages of testing, presents testimonials from patients, and shows graphic illustrations to promote an informed decision. Viewers are asked to consider 3 questions in making a decision about screening: (1) What happens if your PSA level is elevated? (2) What happens if indeed you are found to have cancer? (3) What difference will it make for you to know that you have cancer? Viewers are encouraged to discuss screening with their doctors. A brochure accompanies the videotape and includes many of the tables shown in the tape.

\section{Control Group}

The control subjects received no intervention materials at the baseline assessment. After the 2-week follow-up assessment, they received a 1 -page educational brochure through the mail. The educational brochure had content similar to that in the videotape brochure, including information about the primary advantages and disadvantages of screening. 


\section{Outcome Measures}

As part of the 1-year follow-up assessment, subjects were asked whether they had been screened for prostate cancer in the year since their participation in the study. Three questions were used to evaluate screening. First, subjects were asked if they had had a general physical examination or health check-up during the previous year. This information provided an indicator of the opportunity for screening in the 2 study groups. Two questions were then asked about having a digital rectal examination (DRE) and a PSA test for prostate cancer. Subjects had been asked at the 2-week follow-up assessment about their intentions to be screened by having a PSA test in the following year.

Satisfaction with the screening decision was measured by using an adapted version of the Satisfaction with Decision Scale (SWD) developed by HolmesRovner and associates. ${ }^{14}$ The 6 -item SWD scale is a measure of patient satisfaction with treatment decisions. In our adaptation, we framed the satisfaction questions to specify the prostate cancer screening decision. The response options use a 5 -point Likert scale ranging from "strongly agree" to "strongly disagree."

A major outcome variable was core knowledge of prostate cancer and screening. To allow us to measure deterioration of knowledge since the baseline assessment, we readministered the PC-Know, a 10-item selfreport measure developed previously for this study. ${ }^{15}$ The measure was responsive to changes in core knowledge from the baseline to the 2-week assessment. Finally, subjects were asked to identify any new sources of information about prostate cancer screening they had sought over the previous year, including Internet sources.

\section{Statistical Methods}

Characteristics of the intervention and control subjects were compared. In addition, participants in the 1-year follow-up were compared to those lost to follow-up on selected baseline indicators. There was no need to perform the outcome analyses based on intention-to-treat because all intervention subjects viewed the entire videotape. Rates of screening behavior reported at the 1 -year follow-up for the 2 study groups were evaluated using contingency tables with $\chi^{2}$ as the test statistic. We also examined the relationship between subjects' intentions to be screened as reported at the 2-week follow-up and their subsequent screening behavior.

Differences in scores on the SWD scale were tested using $t$-tests, with means and $95 \%$ confidence limits reported. Changes in core knowledge from the baseline to 1 -year follow-up about prostate cancer in the
2 groups were examined using repeated-measures analysis of variance (ANOVA). In a post-hoc analysis, rates of screening in patients in the intervention group were compared across ethnicity of the subject (white and African American, the 2 largest groups in the study). The latter analysis was conducted because African American ethnicity is a risk factor for prostate cancer incidence and mortality. ${ }^{1}$

Statistical power for this study was estimated using the anticipated rates of PSA testing reported at the 2 -week follow-up. Using the 2 -week data on intention to be screened, we expected that approximately $80 \%$ of the control subjects and $60 \%$ of the intervention subjects would be tested by the time of the 1 -year follow-up. With 67 control subjects and 70 intervention subjects in the 1 -year follow-up, and a type I error rate of .05 , statistical power for this difference would exceed $70 \%$. As the screening rate in the intervention group approached $55 \%$, power would increase to 90\%. ${ }^{16}$ Data were analyzed using Statistical Package for the Social Sciences (SPSS) for Windows, version 10.0. ${ }^{17}$

\section{RESULTS}

\section{Participant Flow and Characteristics}

Figure 1 depicts the study flow. Of the 160 subjects originally enrolled in the study, $70(87.5 \%)$ of the videotape intervention subjects and 67 (83.8\%) of the control subjects participated in the 1 -year follow-up. Characteristics of the sample at the 1-year follow up are shown in Table 1 . There were no significant differences between the subjects who participated in the follow-up and those who did not with regard to sample characteristics, initial group assignment, or outcomes at 2 weeks.

\section{Screening Behavior}

Table 2 reports the number of subjects from each group who, during the follow-up period, had a general physical examination and reported a DRE or PSA test for prostate cancer. More than $70 \%$ of the subjects in each group had a physical examination at some time during the 1 -year follow-up. Almost $40 \%$ of the subjects reported having a DRE. The only group differences were observed for PSA testing: 24 of 70 (34.3\%) intervention subjects reported having a PSA test, whereas 37 of 67 (55.2\%) control subjects reported testing $(P=.01)$. This difference may be interpreted as follows: for every 5 subjects who viewed the videotape intervention, 1 fewer subject was screened for prostate cancer with the PSA test than among the control subjects. Post-hoc analyses of reported PSA testing among intervention subjects showed that 


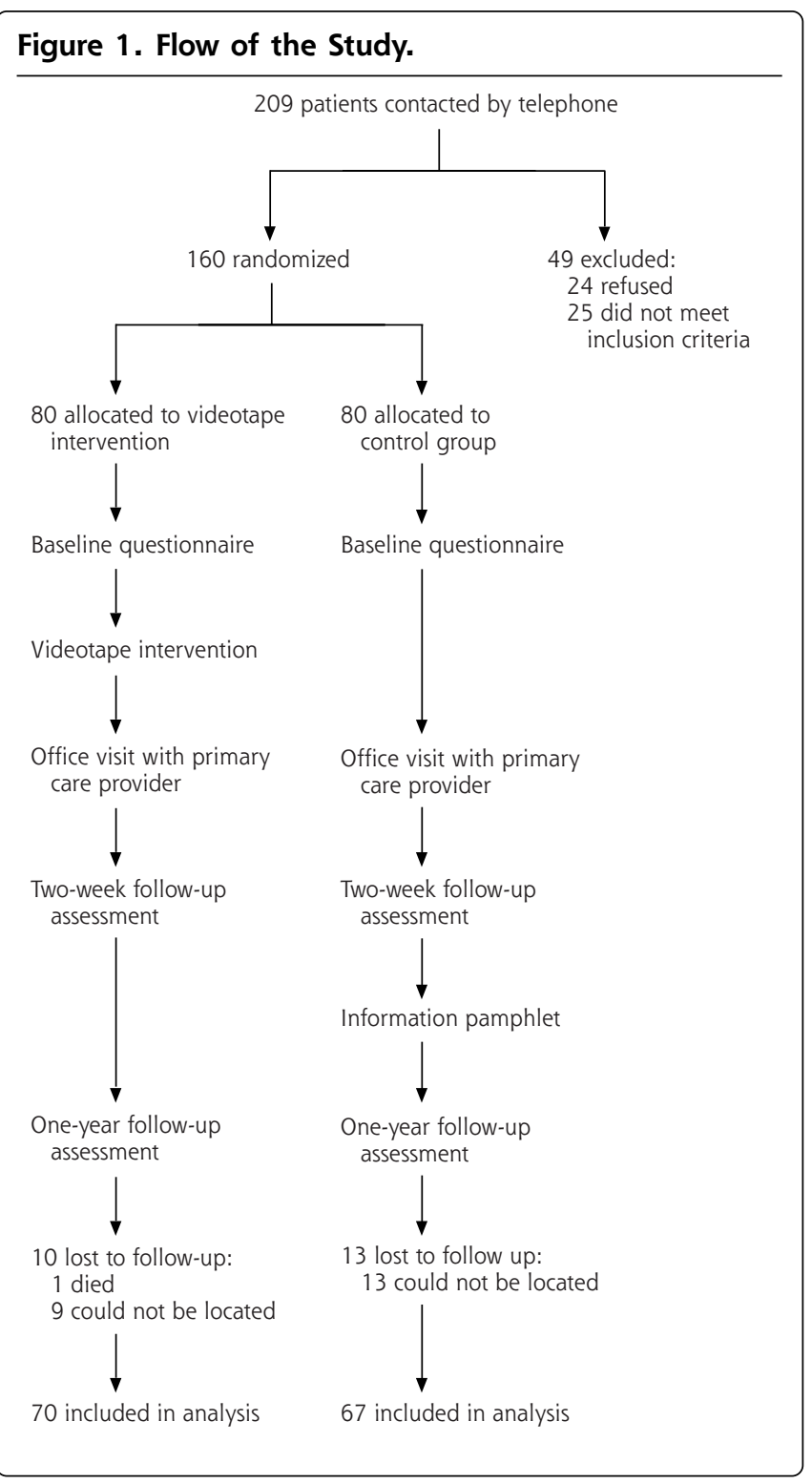

African American men were more likely to have been screened ( 9 of $16,56.3 \%$ ) than white men (13 of 46 , $28.3 \%)\left(\chi_{(1)}^{2}=4.06, P=.044\right)$.

\section{Previous Intentions to be Screened and Screening Behavior at 1 Year}

The relationship between subjects' screening intentions at the 2 -week follow-up and their subsequent screening behavior is shown in Table 3 . Intervention subjects who, at the 2 -week follow-up, indicated that they intended to be screened were equally as likely as control subjects to report having had PSA testing at the 1-year follow-up. Twelve of the intervention subjects indicated that they did not intend to be screened in the following year, compared to none of the control subjects. Of the 12 intervention subjects who intended not to be screened, only 1 reported having had a PSA test at the 1 -year follow-up.

\section{New Sources of Information about Screening}

Few subjects sought additional information about prostate cancer screening from baseline to the 1year follow-up. Television was cited as the most frequently noted source of new information (fewer than $12 \%$ of subjects); the Internet was used the least (only 2 subjects). There were no differences between intervention and control subjects with regard to the sources they used to gather new information about prostate cancer screening.

\section{Satisfaction with the Screening Decision}

The intervention subjects (group mean, 24.3; 95\% CI, 23.7 to 25.0 ) and control subjects (group mean, $23.8 ; 95 \% \mathrm{CI}, 22.9$ to 24.7 ) did not differ in satisfaction with their screening decision during the past year.

\section{Knowledge of Prostate Cancer and Screening}

Figure 2 compares prostate cancer knowledge for the intervention and control subjects from the baseline period to the 2-week and 1-year followups. The percentage of knowledge questions answered correctly at baseline was approximately $30 \%$ in each group. At the 2 -week follow-up, knowledge among the intervention subjects increased significantly (mean score, $48.7 \%$ of questions answered correctly). By the 1 -year follow-up, knowledge had declined among the intervention subjects (mean score, $38.4 \%$ of questions answered correctly). Knowledge among control subjects did not change. The group differences were statistically significant across the data-collection periods ( $F$-ratio from repeated-measures ANOVA $=12.98, P<.001)$.

\section{DISCUSSION}

This follow-up study of an education videotape intended to promote informed decision-making about prostate cancer screening demonstrates that a decision aid can affect patient screening behavior and knowledge fully 1 year after the intervention. The relationship between intentions to be screened reported by patients at the 2 -week follow-up and their subsequent screening behavior suggests that the educational program is largely responsible for the differences in the screening rates observed in this study. In the case of prostate cancer screening, it appears 


\begin{tabular}{|c|c|c|}
\hline & $\begin{array}{l}\text { Intervention Group } \\
\quad(n=70)\end{array}$ & $\begin{array}{c}\text { Control Group } \\
(n=67)\end{array}$ \\
\hline \multicolumn{3}{|l|}{ Age } \\
\hline Mean & 58.9 & 59.7 \\
\hline Standard Deviation & 7.38 & 7.75 \\
\hline Minimum, Maximum & 46,70 & 45,70 \\
\hline \multicolumn{3}{|l|}{ Education } \\
\hline Not a high school graduate & $13(18.6 \%)$ & $17(25.5 \%)$ \\
\hline High school graduate & $11(15.7 \%)$ & $15(22.4 \%)$ \\
\hline Some college training & $27(38.6 \%)$ & $16(23.9 \%)$ \\
\hline College graduate & $19(27.1 \%)$ & $19(28.4 \%)$ \\
\hline \multicolumn{3}{|l|}{ Ethnicity } \\
\hline African American & $16(22.9 \%)$ & $8(11.9 \%)$ \\
\hline white & $46(65.7 \%)$ & $44(65.7 \%)$ \\
\hline Mexican American & $6(8.6 \%)$ & $12(17.9 \%)$ \\
\hline Other & $2(2.9 \%)$ & $3(4.5 \%)$ \\
\hline \multicolumn{3}{|l|}{ Annual Household Income } \\
\hline Less than $\$ 10,000$ & $10(14.3 \%)$ & $14(20.9 \%)$ \\
\hline$\$ 10,000$ to $\$ 19,999$ & $13(18.6 \%)$ & $16(23.9 \%)$ \\
\hline$\$ 20,000$ to $\$ 39,999$ & $20(28.6 \%)$ & $14(20.9 \%)$ \\
\hline$\$ 40,000$ to $\$ 69,999$ & $20(28.6 \%)$ & $16(23.9 \%)$ \\
\hline$\$ 70,000$ and greater & $7(10.0 \%)$ & $7(10.4 \%)$ \\
\hline Family History of Prostate Cancer & $11(15.7 \%)$ & $8(11.9 \%)$ \\
\hline
\end{tabular}

that the informed patient is less likely to pursue PSA testing; however, this result may be influenced by ethnicity or risk perceptions.

An impact of the intervention on screening behavior was observed for PSA testing but not for DRE. Several factors may explain this finding. First, while the videotape includes narration saying that both PSA testing and DRE are components of prostate cancer screening, its emphasis is largely on becoming informed about PSA testing specifically (eg, the program title lists only the PSA test). Patients may thus have assumed that prostate cancer screening and PSA testing were synonymous. Second, the DRE is often performed during a general physical examination. Many physi-

\section{Table 2. Self-Reported Prostate Cancer Screening at 1-Year Follow-up}

\begin{tabular}{|c|c|c|c|c|c|}
\hline & \multicolumn{2}{|c|}{$\begin{array}{l}\text { Intervention Group } \\
(\mathrm{n}=70)\end{array}$} & \multicolumn{2}{|c|}{$\begin{array}{l}\text { Control Group } \\
(n=67)\end{array}$} & \multirow[t]{2}{*}{$P$ value } \\
\hline & $\mathrm{n}$ & $\%$ & $\mathbf{n}$ & $\%$ & \\
\hline $\begin{array}{l}\text { General Physical } \\
\text { Examination }\end{array}$ & 59 & 72.9 & 59 & 76.1 & .89 \\
\hline DRE & 26 & 37.1 & 26 & 38.8 & .84 \\
\hline PSA test & 24 & 34.3 & 37 & 55.2 & .01 \\
\hline
\end{tabular}

cians use the DRE to test for fecal occult blood in screening for colorectal cancer, ${ }^{18,19}$ and patients may not be clear about the reason for the DRE. The comparable DRE rates in this study, nearly $40 \%$ per group, suggest that this may have been the case.

Despite the overall effect of a decrease in PSA testing, African American men who viewed the videotape were almost twice as likely as white men to have been screened by the time of the 1-year follow-up. One possible explanation for this finding is that African American men may have focused on the portions of the videotape that dealt with ethnicity and prostate cancer risk, in which the increased risk for prostate cancer among these men was presented. Awareness of increased risk has been shown to affect the willingness of African American men to undergo PSA testing. ${ }^{20}$ Yet, much of the between-group differences in screening rates could be attributed to the fact that only $28.3 \%$ of the white men in the intervention group reported having had the test.

The role of trust in the physician-patient relationship and preferences among patients for their role in decision making may explain some of these differences. ${ }^{21}$ These ethnicgroup-specific findings should be investigated in future studies, because decision aids may need to be tailored to such patient characteristics.

Previous studies of decision aids for prostate cancer screening have shown a variable impact on screening behavior. In studies in which patients were presenting for screening (eg, free screening clinics or solicited by mail), decision aids have had no impact on screening rates because nearly all patients opted to be screened. ${ }^{7,8}$ Studies of patients presenting for routine primary care have shown a lower screening rate among those receiving a decision-aid intervention compared to other patients presenting specifically for screening. ${ }^{7,9,10}$ One exception is a study Davison et $\mathrm{al}^{22}$ conducted with male primary care patients presenting for periodic health examinations, which found that intervention (verbal and written material about screening) and control patients had similar rates of DRE and PSA testing. We have argued elsewhere that these differences can be attributed primarily to the populations studied and the nature of the decision-making process. ${ }^{12}$

In our study, knowledge of prostate cancer and screening was 
Table 3. Relationship Between Intention to Be Screened as Reported at the 2-week Follow-Up and Reported PSA Testing at the 1-Year Follow-up

\begin{tabular}{lcc}
\hline Intentions & $\begin{array}{c}\text { Intervention } \\
\text { group* }\end{array}$ & Control group \\
Intended to have PSA test & 40 & 57 \\
Reported being tested at 1-year follow-up & $21(52.5 \%)$ & $33(57.9 \%)$ \\
Intended to not have PSA test & 12 & 0 \\
Reported being tested at 1-year follow-up & $1(8.3 \%)$ & 0 \\
Was unsure about PSA testing & 17 & 10 \\
Reported being tested at 1-year follow-up & $2(11.8 \%)$ & $4(40.0 \%)$ \\
\hline PSA: prostate-specific antigen. & & \\
*Two-week follow-up data for 1 patient in the intervention group is missing. & \\
\hline
\end{tabular}

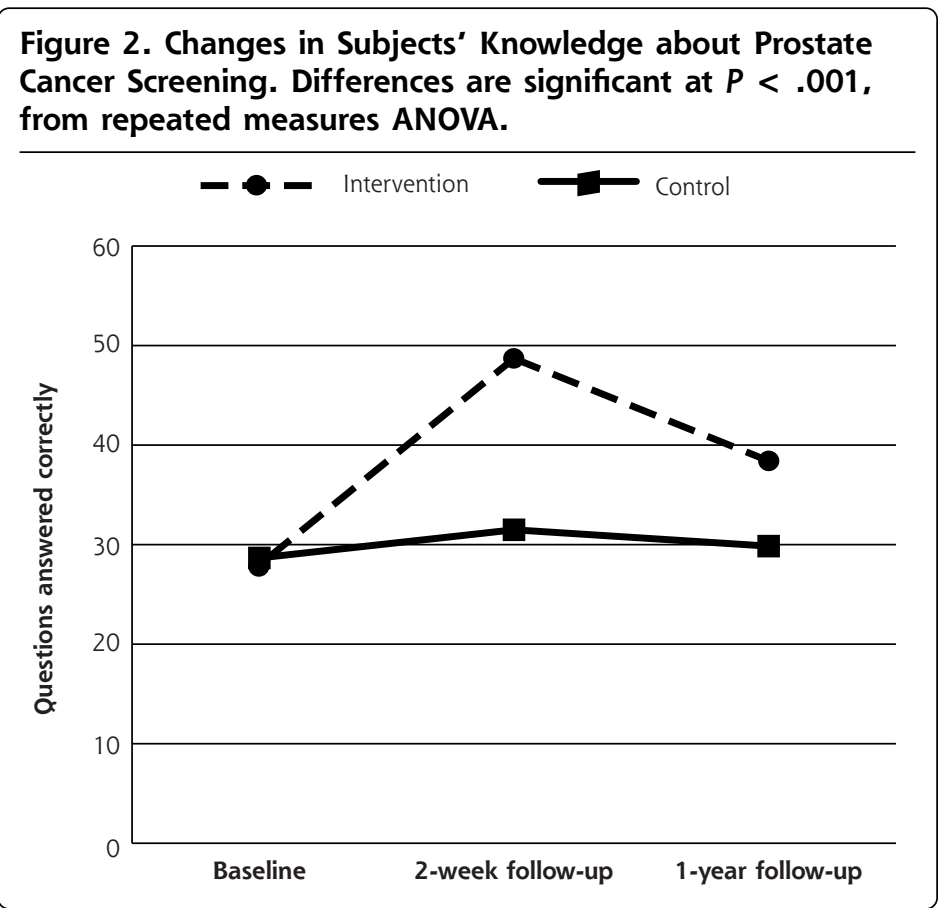

quently, patients may receive more benefit from brief reminders that highlight the importance of screening than from an intensive intervention such as a decision aid. ${ }^{23}$

Our study has a number of important limitations. It was conducted at a single clinical site. Furthermore, participation in the study may have affected screening rates and knowledge, because patients provided data at 3 separate data-collection times. The accuracy of patients' self-reported PSA testing may be suspect, because patients can be screened outside of their primary care provider's office, and many patients may not be aware of the purpose of the blood test. ${ }^{24}$ Finally, the effect of the provider in the decision-making process was not examined. The importance of physician advice in cancer screening utilization, such as mammography, is well established, ${ }^{25-27}$ and a specific effect on prostate cancer screening has been demonstrated in other studies. ${ }^{28}$

Decision aids for prostate cancer screening may be beneficial to patients in promoting informed decision making. Our study suggests that decision aids may also affect screening behaviors. A significant remaining challenge is determining how to integrate the use of decision aids into routine clinical practice. The competing demands of the office visit suggest that these aids must be used as an adjunct to visits, perhaps be limited to periodic health examinations, and should be viewed before the patient sees the primary care provider. Although prostate cancer screening is among the most extensively researched areas in decision-aid development, new approaches to the integration of educational tools (such as the

superior in subjects who viewed the videotape, compared to that in control subjects. Not surprisingly, the initial gains largely had been lost by the 1-year followup, although the intervention subjects continued to demonstrate slightly greater knowledge. This finding raises the issue of the need for subsequent educational interventions, or boosters, to help patients remain informed as they consider screening in the future. Although it might be argued that the screening decision needs to be made only once, more recent research and evidence suggest that the screening issue should be revisited periodically. In the case of colorectal cancer, for example, screening (eg, fecal occult blood test) may be required annually, which means that patients would have to revisit their screening decision repeatedly. Conse- videotape evaluated in our study) into clinical practice and among different patient populations are needed.

To read commentaries or to post a response to this article, see the online version at http://www.annfammed.org/cgi/content/full/1/1/22.

Key words: Patient Education, Primary Health Care, Prostate Neoplasms, Medical Decision Making/Informatics

Received August 29, 2002; accepted November 4, 2002

Presented in part at the annual meetings of the North American Primary Care Research Group and the Society for Medical Decision Making in 1998.

\section{Financial support}

The authors acknowledge grants from the American Academy of Family Physicians Foundation and the 
American Academy of Family Physicians, Leawood, $\mathrm{Ks}$; the Bureau of Health Professions, Health Resources and Services Administration, Rockville, Md (D32-PE10158-01); and the Agency for Healthcare Research and Quality (K02-HS00007-02 to STH).

\section{Acknowledgments}

The authors acknowledge the assistance of Kristi J. O'Dell, PhD, Carol Carlson, Joal Hill, JD, PhD, and Anna Catalina Triana, MD, in collecting data, and Pamela Paradis Tice, ELS(D), in editing the manuscript.

The videotape, The PSA Decision: What YOU Need to

Know, was used in the study with the permission of the Foundation for Informed Medical Decision Making, Inc. The videotape is distributed through Health Dia$\log$, Inc, which can be accessed at http://www.healthdialog.com.

The authors of this study have no relationship with the Foundation for Informed Medical Decision Making Inc, or with Health Dialog Inc.

\section{REFERENCES}

1. American Cancer Society. Cancer Facts \& Figures 2002. Atlanta, Ga: American Cancer Society; 2002.

2. Smith RA, Mettlin CJ, Davis KJ, Eyre H. American Cancer Society guidelines for the early detection of cancer. CA Cancer J Clin 2000;50:34-39.

3. American Urological Association. Prostate-specific antigen (PSA) best practice policy. Oncology (Huntingt) 2000;14:267-272, 277-278, 280 passim.

4. Ferrini R, Woolf SH. American College of Preventive Medicine Practice Policy: Screening for prostate cancer in American men. Am J Prev Med 1998;15:81-84.

5. US Preventive Services Task Force. Guide to clinical preventive services: report of the US Preventive Service Task Force. 2nd ed. Baltimore, Md: Williams \& Wilkins; 1996.

6. Spann SJ. Prostate cancer screeningæwhat's a physician to do? [editorial]. Am Fam Physician 1997;56:1563-1564, 1567-1568.

7. Flood AB, Wennberg JE, Nease RF Jr, Fowler FJ Jr, Ding J, Hynes LM. The importance of patient preference in the decision to screen for prostate cancer. Prostate Patient Outcomes Research Team. J Gen Intern Med 1996;11:342-349.

8. Schapira MM, VanRuiswyk J. The effect of an illustrated pamphlet decision-aid on the use of prostate cancer screening tests. J Fam Pract 2000;49:418-424

9. Wilkins EG, Lowery JC, Hamill JB. The impact of shared decisionmaking in prostate specific antigen (PSA) screening [abstract]. Med Decis Making 1999;19:525.

10. Frosch DL, Kaplan RM, Felitti V. The evaluation of two methods to facilitate shared decision making for men considering the prostatespecific antigen test. J Gen Intern Med 2001;16:391-398.

11. Wolf AM, Nasser JF, Schorling JB. The impact of informed consent on patient interest in prostate-specific antigen screening. Arch Intern Med 1996;156:1333-1336.

12. Volk RJ, Spann SJ. Decision-aids for prostate cancer screening. J Fam Pract 2000;49:425-427.

13. Volk RJ, Cass AR, Spann SJ. A randomized controlled trial of shared decision making for prostate cancer screening. Arch Fam Med 1999; 8:333-340.

14. Holmes-Rovner M, Kroll J, Schmitt N, et al. Patient satisfaction with health care decisions: the satisfaction with decision scale. Med Decis Making 1996;16:58-64.

15. O’Dell KJ, Volk RJ, Cass AR, Spann SJ. Screening for prostate cancer with the prostate-specific antigen test: are patients making informed decisions? J Fam Pract 1999;48:682-688.

16. Hintze JL. Power Analysis and Sample Size for Windows. Version 6.0. Kaysville, Utah: NCSS; 1996.

17. Statistical Package for the Social Sciences. Version 11.0.1. Chicago, III: SPSS Inc; 2001.

18. Hawley ST, Foxhall L, Vernon SW, Levin B, Young JE. Colorectal cancer screening by primary care physicians in Texas: a rural-urban comparison. J Cancer Educ 2001;16199-16204.

19. Hawley ST, Levin B, Vernon SW. Colorectal cancer screening by primary care physicians in two medical care organizations. Cancer Detect Prev 2001;25:309-318.

20. Myers RE, Wolf TA, Balshem AM, Ross EA, Chodak GW. Receptivity of African-American men to prostate cancer screening. Urology 1994;43:480-487

21. Collins TC, Clark JA, Petersen LA, Kressin NR. Racial differences in how patients perceive physician communication regarding cardiac testing. Med Care 2002;40(1 Suppl):127-34.

22. Davison BJ, Kirk P, Degner LF, Hassard TH. Information and patient participation in screening for prostate cancer. Patient Educ Counsel 1999; $37: 255-263$

23. Halabi S, Skinner CS, Samsa GP, Strigo TS, Crawford YS, Rimer BK. Factors associated with repeat mammography screening. J Fam Pract 2000;49:1104-1112.

24. Volk RJ, Cass AR. The accuracy of primary care patients' self-reports of prostate- specific antigen testing. Am J Prev Med 2002;22:56-58.

25. Hawley ST, Earp JA, O'Malley M, Ricketts TC. The role of physician recommendation in women's mammography use: is it a 2-stage process? Med Care 2000;38:392-403.

26. O'Malley MS, Earp JA, Hawley ST, Schell MJ, Mathews HF, Mitchell J. The association of race/ethnicity, socioeconomic status, and physician recommendation for mammography: who gets the message about breast cancer screening? Am J Public Health 2001;91:49-54.

27. Simon MS, Gimotty PA, Coombs J, McBride S, Moncrease A, Burack RC. Factors affecting participation in a mammography screening program among members of an urban Detroit health maintenance organization. Cancer Detect Prev 1998;2230-2238.

28. Steele CB, Miller DS, Maylahn C, Uhler RJ, Baker CT. Knowledge, attitudes, and screening practices among older men regarding prostate cancer. Am J Public Health 2000;90:1595-1600. 